\title{
Loss of FGL1 induces epithelial-mesenchymal transition and angiogenesis in LKB1 mutant lung adenocarcinoma
}

\author{
FENGLONG BIE $^{1 *}$, GUANGHUI WANG ${ }^{1,2^{*}}$, XIAO QU $^{1}$, YADONG WANG $^{1}$, \\ CUICUI HUANG ${ }^{1}$, YU WANG ${ }^{1}$ and JIAJUN DU ${ }^{1,2}$ \\ ${ }^{1}$ Institute of Oncology and ${ }^{2}$ Department of Thoracic Surgery, \\ Shandong Provincial Hospital Affiliated to Shandong University, Jinan, Shandong 250021, P.R. China
}

Received November 1, 2018; Accepted July 4, 2019

DOI: 10.3892/ijo.2019.4838

\begin{abstract}
Liver kinase b1 (LKB1) is a tumor suppressor, and the inactivated mutation frequency of LKB1 in lung adenocarcinoma is $\sim 20 \%$. The present study aimed to explore potential novel biomarkers in LKB1 mutant lung adenocarcinoma. Gene expression data from lung adenocarcinoma patients were downloaded from The Cancer Genome Atlas and the Gene Expression Omnibus databases. $\mathrm{R}$ software was used to analyze the gene expression profiles. Reverse transcription-quantitative PCR (RT-qPCR), western blot and immunohistochemistry (IHC) analyses were used to examine gene expression and function. Gene function was further explored via gene set enrichment analysis. A colony formation assay was used to evaluate cell proliferation. A wound-healing assay and immunofluorescence analysis were used to evaluate cell migration and epithelial-mesenchymal transition (EMT), respectively. Wound healing assay, immunofluorescence, western blot, RT-qPCR and IHC results for EMT-associated markers demonstrated that a loss of fibrinogen-like 1 (FGL1) induced EMT in LKB1 mutant lung adenocarcinoma. RT-qPCR and IHC analyses of angiogenesis-related markers revealed that loss of FGL1 promoted angiogenesis in LKB1 mutant lung adenocarcinoma. Overall, the present results demonstrated that loss of FGL1 induced EMT and angiogenesis in LKB1 mutant lung adenocarcinoma. FGL1 may be a novel biomarker to indicate EMT and angiogenesis in patients with LKB1 mutant lung adenocarcinoma.
\end{abstract}

Correspondence to: Professor Jiajun Du, Institute of Oncology, Shandong Provincial Hospital Affiliated to Shandong University, 324 Jingwu Road, Jinan, Shandong 250021, P.R. China

E-mail: dujiajun@sdu.edu.cn

*Contributed equally

Key words: liver kinase b1, fibrinogen-like 1, lung adenocarcinoma, epithelial-mesenchymal transition, angiogenesis

\section{Introduction}

Lung cancer is the leading cause of cancer-related death worldwide and results in $>1$ million deaths annually (1). The most common type of lung cancer is the non-small cell lung cancer (NSCLC), which mainly comprises lung adenocarcinoma and squamous cell carcinoma (2). Lung adenocarcinoma is the most common form of lung cancer, and its 5 -year survival rate is only 15\% (3). Although many treatment modalities exist for lung adenocarcinoma, such as surgery, radiotherapy, chemotherapy and targeted treatment, the prognosis for patients with lung cancer is poor because of various complications and diagnosis at late stages $(4,5)$. The present study explored potential novel biomarkers in liver kinase b1 (LKB1) mutant lung adenocarcinoma. Bioinformatic data mining and experimental verification revealed that FGL1 was highly expressed in LKB1 mutant lung adenocarcinoma. Then, the functional role of FGL1 in LKB1 mutant lung adenocarcinoma was further explored.

LKB1, also known as serine/threonine kinase 11 (STK11), is a gene encoding the serine/threonine kinase LKB1, which was originally identified as the tumor suppressor gene for the inherited cancer disorder Peutz-Jeghers syndrome (6). The inactivated mutation frequency of LKB1 in NSCLC is $\sim 20 \%$ (7). The most common target of LKB1 is AMP-activated protein kinase (AMPK), which is directly phosphorylated and activated by LKB1 under conditions of low cellular ATP (8). LKB1 can activate AMPK-related family kinases to regulate many aspects of cell metabolism, growth, autophagy and polarity $(8,9)$. LKB1 mutations can lead to tumor initiation and confer invasive and metastatic behavior in genetically engineered mouse models of cancer $(10,11)$. The present study focused on LKB1 mutant lung adenocarcinoma and explored novel biomarkers to diagnose and treat this subcategory of patients.

Fibrinogen-like protein 1 (FGL1), also termed HRFEP-1 or hepassocin, is a predominantly liver-expressed protein that functions as both a hepatoprotectant and a hepatocyte mitogen. In 1993, Yamamoto et al (12) isolated FGL1 from a cDNA library constructed from the mRNA of a hepatocellular carcinoma specimen using subtractive and differential cDNA cloning and demonstrated that this gene was important in the development of hepatocellular carcinoma. Rijken et al (13) 
concluded that FGL1, a protein with livercell growth regulatory properties, was found in plasma and was strongly associated with fibrin and possibly fibrinogen. Nayeb-Hashemi et al (14) reported that FGL1 was a tumor suppressor in hepatocellular carcinoma, and its loss correlated with a poorly differentiated phenotype. Although several studies have shown an association of FGL1 with liver cancer, few studies have investigated the role of FGL1 in lung cancer.

In the present study, data mining of The Cancer Genome Atlas (TCGA) (15) and the Gene Expression Omnibus (GEO) (16) databases revealed that FGL1 expression was significantly increased in LKB1 mutant lung adenocarcinoma. The association between LKB1 and FGL1 was explored viafunctional experiments and gene set enrichment analysis (GSEA); the results confirmed that FGL1 regulated epithelial-mesenchymal transition (EMT) and angiogenesis in LKB1 mutant lung adenocarcinoma. The present study demonstrated that FGL1 may serve as a potential novel biomarker for diagnosis and prognosis in patients with LKB1 mutated lung adenocarcinoma.

\section{Materials and methods}

Database source and gene expression. Using the TCGA database, lung adenocarcinoma information on 230 patients with LKB1 mutations were acquired (7). Separate differential gene expression analyses were conducted using the edgeR and DESeq packages in R software (r-project.org/, $\mathrm{R}$ x64 3.4.3), and the intersection of the differentially expressed genes $[\log \mathrm{FCl}>1$ and false discovery rate $(\mathrm{FDR})<0.05]$ from these two packages was obtained. Two GEO databases (GSE72094 and GSE75037) $(17,18)$ were then used to validate these differentially expressed genes and the intersected/validated genes from TCGA and the two GEO databases were finally selected. Fig. 1 illustrates a flow-chart for the gene screening process.

Patient selection. Tissue samples from 30 patients (13 male, 17 female) with lung adenocarcinoma who underwent surgery at Shandong Provincial Hospital affiliated to Shandong University in 2018 were enrolled in this study. Tumor tissue was collected from patients that met the following inclusion criteria: The patient has only one cancer, lung cancer; there is only one lesion and the pathological diagnosis is simple lung adenocarcinoma; tumor size $2-4 \mathrm{~cm}$; the range of age is 40-60 years old; the specific surgery dates were between October to December 2018. Patients that did not meet the inclusion criteria were excluded. Informed consent was obtained from all participants included in the study. All procedures conformed to the ethical guidelines of the 1975 Declaration of Helsinki and were in accordance with the ethical standards of the Ethics Committee of Shandong Provincial Hospital Affiliated to Shandong University. The Ethics Committee of Shandong Provincial Hospital Affiliated to Shandong University approved all experimental protocols.

Cell cultures and antibodies. The LKB1 mutant lung adenocarcinoma cell lines (A549 and H157), the LKB1 mutant large cell lung cancer cell line (H460) and 293T cells were purchased from the American Type Culture Collection. A549, H157 and H460 cells were cultured in RPMI-1640 medium and 293T cells were cultured in high glucose DMEM (both from HyClone; GE Healthcare Life Sciences) supplemented with 10\% (FBS; Biological Industries). Cells were grown at $37^{\circ} \mathrm{C}$ in a humidified atmosphere with $5 \% \mathrm{CO}_{2}$. Mouse monoclonal antibody against GAPDH (cat. no. sc-166545), mouse monoclonal antibody against FGL1 (cat. no. sc-514057), mouse monoclonal antibody against $\mathrm{N}$-cadherin $(\mathrm{CDH} 2$; cat. no. sc-59987, for IHC), mouse monoclonal antibody against vascular endothelial growth factor (VEGF)A (cat.no. sc-152) and mouse monoclonal antibody against LKB1 (cat. no. sc-32245) were purchased from Santa Cruz Biotechnology, Inc. Rabbit monoclonal antibodies against E-cadherin (CDH1; cat. no. 3195s) and vimentin (VIM; cat. no. 5741P) were purchased from Cell Signaling Technology, Inc. Rabbit monoclonal antibody against $\mathrm{CDH} 2$ (cat. no. ab76011; used for western blotting) was purchased from Abcam.

Construction of the LKB1 cell line. HEK293T cells were transfected with virus packaging plasmid (psPAX2; Addgene, Inc.; cat. no. 12260; pMD2.G, Addgene, Inc.; cat. no. 12259) and pLenti-EF1a-mcherry-P2A-Puro-CMV-MCS-3Flag (control) or pLenti-EF1a-mcherry-P2A-Puro-CMV-LKB1 [encoding the wild-type LKB1 protein; made by OBiO Technology (Shanghai) Corp., Ltd.] stable plasmids using transfection reagent (jetPRIME ${ }^{\circledast}$ in vitro DNA and siRNA transfection reagent; Polyplus-transfection ${ }^{\circledR}$ SA). After the HEK293T cells were transfected for $48 \mathrm{~h}$, the supernatant was collected and added to infect A549 cells for $24 \mathrm{~h}$. A549 cells were then subjected to puromycin selection ( $4 \mathrm{ng} / \mu \mathrm{l}$ ) for 1 to 2 weeks, and puromycin-resistant stable clones were collected. Expression of LKB1 in the established stably transfected A549 cells was validated via western blotting.

Small interfering RNA (siRNA). Transfection was performed using transfection reagent (jetPRIME ${ }^{\circledR}$ in vitro DNA and siRNA transfection reagent; Polyplus-transfection ${ }^{\circledR}$ SA). Cells in 6-well plates were grown to $\sim 50 \%$ confluence, then the media was replaced with fresh complete culture medium prior to transfection. Cells were then transfected with four different FGL1-targeting sequences (50 nM) (TranSheepBio), following the manufacturer's instructions. The sequences of the siRNAs are as follows: Negative Control, sense, 5'-UUCUCCGAACGU GUCACGUdTdT-3' and antisense, 5'-ACGUGACACGUUC GGAGAAdTdT-3'; FGL1-1, sence, 5'-GAAGUCCAGUUCCU UGAUAdTdT-3' and antisense, 5'-UAUCAAGGAACUGGA CUUCdTdT-3'; FGL1-2, sense, 5'-GCCGUUAUGCACAAUAU AAdTdT- 3 ' and antisense, 5'-UUAUAUUGUGCAUAACGGCd TdT-3'; FGL1-3, 5'-CUAGUCACCAAAGAAUGAAdTdT-3' and antisense, 5'-UUCAUUCUUUGGUGACUAGdTdT-3'; FGL1-4, sense, 5'-GGGCUAGUCACCAAAGAAUdTdT-3' and antisense, 5'-AUUCUUUGGUGACUAGCCCdTdT-3'. The transfected cells were incubated for $24 \mathrm{~h}$, then the medium was replaced with complete medium. A $48 \mathrm{~h}$ post-transfection, the cells were divided into two dishes, to avoid overconfluency. At $72 \mathrm{~h}$ post-transfection, the efficiency of the siRNAs was examined by reverse transcription-quantitative PCR (RT-qPCR), and the most effective siRNAs were used for subsequent functional experiments.

$R T-q P C R$. RNAiso Plus (Takara Bio, Inc.) was used to lyse the cultured cells and extracted and amplified the RNA from 
Table I. Primers used for reverse transcription-quantitative PCR analysis.

Gene

\section{LKB1}

18S rRNA

FGL1

$\mathrm{CDH} 1$

$\mathrm{CDH} 2$

VIM

TGF- $\beta 1$

VEGFA

VEGFB

HIF-1A

IGF-1

EGFR
Forward primer $\left(5^{\prime}-3^{\prime}\right)$

Reverse primer (5'-3')

TGATGGAGTACTGCGTGTGT
AAACGGCTACCACATCCAAG
GGGTCAAACAGCAACAGGTC
CGGACGATGATGTGAACACC
CGGTTTCATTTGAGGGCACA
TGCAGGCTCAGATTCAGGAA
CTTTCCTGCTTCTCATGGCC
GACGGACAGACAGACAGACA
ATCCTCATGATCCGGTACCC
TCCAAGAAGCCCTAACGTGT
ATCAGCAGTCTTCCAACCCA
AGGTGAAAACAGCTGCAAGG

TGATGGAGTACTGCGTGTGT

GGGTCAAACAGCAACAGGTC

CGGACGATGATGTGAACACC

TGCAGGCTCAGATTCAGGAA

CTTTCCTGCTTCTCATGGCC

GACGGACAGACAGACAGACA

ATCCTCATGATCCGGTACCC

ATCAGCAGTCTTCCAACCCA
AGGTGAAAACAGCTGCAAGG

GCTTGATGTCCTTGTGCACA
CCTCCAATGGATCCTCGTTA
CTCCTCCATCGGACATGTCA
TTGCTGTTGTGCTTAACCCC
TTGGAGCCTGAGACACGATT
CTCCGGTACTCAGTGGACTC
TCCAGGCTCCAAATGTAGGG
CGAGAACAGCCCAGAAGTTG
AGTGGGATGGGTGATGTCAG
TCCAAGAAGCCCTAACGTGT
TGTCTCCACACACGAACTGA
AGGTGATGTTCATGGCCTGA

LKB1, liver kinase b1; rRNA, ribosomal RNA; FGL1, fibrinogen-like 1; CDH1, E-cadherin; CDH2, N-cadherin; VIM, vimentin; TGF, transforming growth factor; VEGF, vascular endothelial growth factor; HIF, hypoxia-inducible factor; IGF, insulin-like growth factor; EGFR, epidermal growth factor receptor.

the cells using a cellular RNA extraction kit (PrimeScript ${ }^{\mathrm{TM}}$ RT reagent Kit with gDNA Eraser). The genomic DNA removal reaction and the RNA RT reaction were performed in accordance with the instruction of the cellular RNA extraction kit. mRNA expression was examined via RT-qPCR with the LightCycler 480 Real-time PCR System, using SYBR Premix Dimer Eraser (Takara Bio, Inc.) reagent in a $20 \mu 1$ reaction volume. Cycling conditions for $\mathrm{qPCR}$ were as follows: Denaturation, $95^{\circ} \mathrm{C}$ for $30 \mathrm{sec}(1 \mathrm{cycle}) ; \mathrm{PCR}, 95^{\circ} \mathrm{C}$ for $5 \mathrm{sec}$, $55^{\circ} \mathrm{C}$ for $30 \mathrm{sec}, 72^{\circ} \mathrm{C}$ for $30 \mathrm{sec}\left(40\right.$ cycles); melting, $95^{\circ} \mathrm{C}$ for $5 \mathrm{sec}, 60^{\circ} \mathrm{C}$ for $1 \mathrm{~min}, 95^{\circ} \mathrm{C}(1 \mathrm{cycle})$; cooling, $50^{\circ} \mathrm{C}$ for $30 \mathrm{sec}$ (1 cycle). The qPCR primers were designed using Primer3 (primer3.ut.ee/). Primer sequences are listed in Table I. Each sample was repeated in triplicate and normalized to $18 \mathrm{~S}$ ribosomal RNA expression. The results were evaluated using the comparative threshold cycle value method $\left(2^{-\Delta \Delta C q}\right)$ (19) for relative quantification of gene expression.

Colony formation assay. After transfecting cells with FGL1 siRNAs for $48 \mathrm{~h}$, the cells were suspended with pancreatin (0.25\% Trypsin-EDTA 1X; Gibco; Thermo Fisher Scientific, Inc.) and plated in $60 \mathrm{~mm}$ dishes (1,000 cells/dish) containing $5 \mathrm{ml}$ of culture medium. The dishes were maintained at $37^{\circ} \mathrm{C}$ with $5 \% \mathrm{CO}_{2}$ and saturated humidity for 7-14 days. The cultivation was terminated when macroscopic colonies appeared in the dishes. After removing the supernatant, the colonies were carefully washed with phosphate-buffered saline (PBS). The cells were then fixed with $4 \%$ paraformaldehyde for $30 \mathrm{~min}$ $\left(25^{\circ} \mathrm{C}\right)$ and stained with $0.1 \%$ crystal violet for $30 \mathrm{~min}\left(25^{\circ} \mathrm{C}\right)$. Finally, the excess dye was washed with running water, and the cells were observed using an optical microscope ( 440 and x100; Leica Microsystems Gmbh). Images of the clone formation were obtained by scanning the cell culture dishes.

Wound healing assay. A wound healing assay was performed to investigate the effect of FGL1 on A549 cell migration. Cell suspensions were prepared and seeded into a 6-well plate with $\sim 5 \times 10^{5}$ cells/well. After culturing for $24 \mathrm{~h}$, the wounds were induced with a 100- $\mu 1$ micropipette tip. Then, the complete RPMI-1640/10\% FBS medium was changed to RPMI-1640 medium with $1 \%$ FBS. The wound widths were photographed using an optical light microscope (Leica Microsystems $\mathrm{GmbH}$ ) at $0,6,12,24,36$ and 48 h post-scratching.

Immunofluorescence analysis. Cells were grown on slides for $24 \mathrm{~h}$ to $50 \%$ confluence. The medium was aspirated and washed twice with PBS. Cells were fixed in $4 \%$ formaldehyde for $10 \mathrm{~min}\left(25^{\circ} \mathrm{C}\right)$, then washed two or three times with PBS. Permeabilization treatment with $0.5 \%$ Triton X-100 was applied for $5 \mathrm{~min}$, then cells were washed two or three times with PBS. Tetramethylrhodamine (TRITC)-labeled phalloidin was applied to the cells at room temperature for $30 \mathrm{~min}$ in the dark, then washed three times with PBS. Nuclei were counterstained with $200 \mu 1$ of DAPI solution (100 nM), washed and covered with PBS, and observed under a fluorescence microscope.

Western blot analysis. Cells were lysed in lysis buffer and the protein concentration was determined via the bicinchoninic acid protein assay. Equal amounts of protein $(15 \mu \mathrm{g}$ protein per lane in the gel) from each cell lysate were subjected to SDS-PAGE (upper layer of gel 5\% concentration; lower layer of gel $10 \%$ concentration) and transferred onto polyvinylidene difluoride membranes. The membranes were blocked in $5 \%$ bovine serum albumin for $1 \mathrm{~h}$ at room temperature and then probed with primary antibodies against LKB1 (dilution 1:2,000), GAPDH (dilution 1:1,500), CDH1 (dilution 1:1,000), CDH2 (dilution 1:5,000) or VIM (dilution 1:1,000) in Tris-buffered saline containing $0.2 \%$ Tween-20 and $5 \%$ fat-free dry milk overnight at $4{ }^{\circ} \mathrm{C}$. After washing, the membrane was incubated with horseradish peroxidase-conjugated secondary antibodies (dilution 1:10,000; cat. no. ZB-2305 for goat anti-mouse; cat. no. ZB-2301 for goat anti-rabbit) (both from OriGene Technologies, Inc.) for $1 \mathrm{~h}$ at room temperature. Immunoreactive bands were visualized using enhanced 
chemiluminescence detection reagent (WesternBright ${ }^{\mathrm{TM}} \mathrm{ECL}$; cat. no. 180805-33; Advansta, Inc.), as per the manufacturer's instructions.

Immunohistochemistry (IHC) staining. Tissue sections $(4 \mu \mathrm{m}$ thick) were cut from formalin-fixed (10\% formalin-fixed at $25^{\circ} \mathrm{C}$ for $24 \mathrm{~h}$ ) paraffin blocks, and used for IHC staining. Anti-LKB1, anti-FGL1, anti-CDH2 and anti-VEGFA (all dilution 1:200; Santa Cruz Biotechnology, Inc.) were used as the primary antibodies. Sections were dewaxed and subjected to antigen retrieval (high pressure method for $3 \mathrm{~min}$ in saline sodium citrate), then incubated with $3 \% \mathrm{H} 2 \mathrm{O} 2$ for $30 \mathrm{~min}$ at $25^{\circ} \mathrm{C}$ to quench endogenous peroxidase activity. Subsequently, 7\% goat serum (OriGene Technologies, Inc.; cat. no. SPN-9001 for goat anti-rabbit kit; cat. no. SPN-9002 for goat anti-mouse kit) was used to block cross-reactivity at $25^{\circ} \mathrm{C}$ for $30 \mathrm{~min}$. Biotin-labelled antibody (1:200; OriGene Technologies, Inc.; cat. no. SPN-9001 for goat anti-rabbit kit; cat. no. SPN-9002 for goat anti-mouse kit), streptavidin-biotin complex (OriGene Technologies, Inc.; cat. no. SPN-9001 for goat anti-rabbit kit; cat. no. SPN-9002 for goat anti-mouse kit) and diaminobenzidine (DAB) were added to the samples after the primary antibodies and incubated at $4^{\circ} \mathrm{C}$ overnight. The same steps were used for the control group, except the primary antibody was substituted with PBS. After dyeing, two observers selected five fields (x400) randomly and scored these specimens according to the intensity of dyed color. The intensity of staining was graded as: 0 , no color; 1 , light yellow; 2, light brown; 3, deep brown. Each observer's scores of five view fields were averaged, and the two observers' scores were also averaged. Scores 0-1 were defined as low expression, and score $\geq 2$ were defined as high expression.

GSEA. GSEA was used to explore selected gene functions. Using the TCGA database, lung adenocarcinoma information on 592 patients were acquired for GSEA analysis. GSEA software $(20,21)$ provides scores based on gene expression and acquired pathways associated with gene function. The presents study used two gene set databases, c5.all.v6.2.symbols. gmt (gene ontology gene sets) and c2.cp.kegg.v6.2 symbols. gmt [curated gene sets, gene sets derived from the Kyoto Encyclopedia of Genes and Genomes (KEGG) pathway database], to analyze the target genes using GSEA 3.0.

Statistical analysis. Data were analyzed using GraphPad Prism 7 (GraphPad Software, Inc.) and three independent experiments were performed. The data are presented as the mean \pm standard deviation. Comparison between two sets of data was performed using unpaired Student's t-test. One-way ANOVA, followed by Dunnett's multiple comparisons test, was used for statistical analysis of $>2$ groups. All P-values were two-sided and $\mathrm{P}<0.05$ was considered to indicate a statistically significant difference.

\section{Results}

$m R N A$ expression profiling. Gene expression information from 230 patients (including 43 LKB1 mutant patients and 187 LKB1 wild-type patients) with lung adenocarcinoma was obtained using TCGA. Next, a differential gene expression analysis

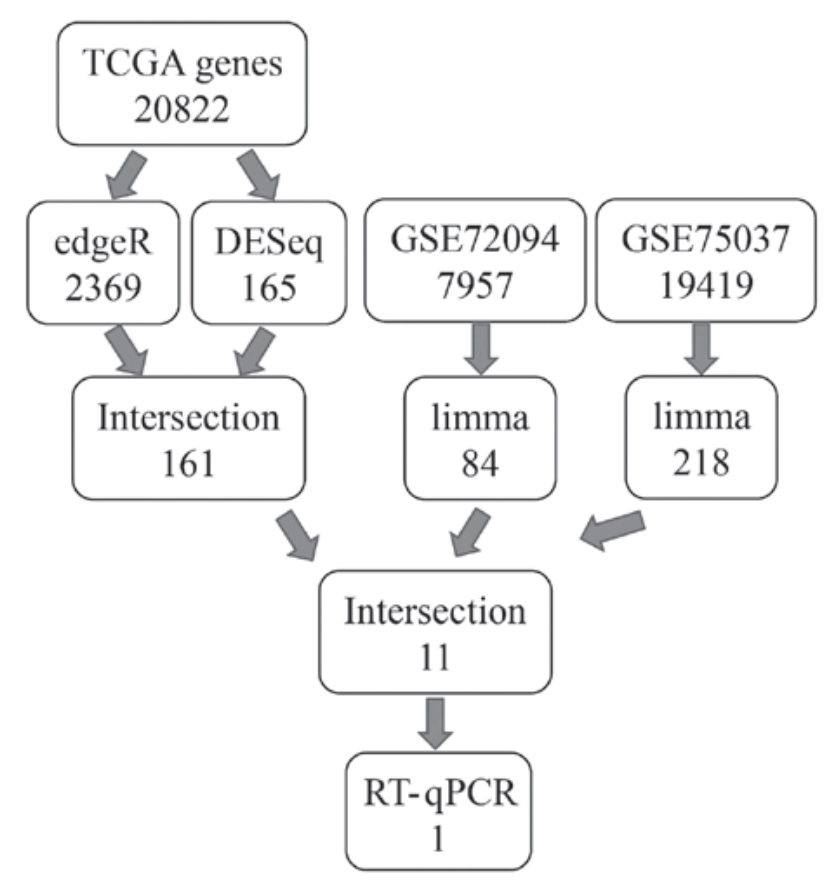

Figure 1. Flow-chart of the gene screening process. TCGA, The Cancer Genome Atlas; RT-qPCR, reverse transcription-quantitative PCR.

was conducted between the LKB1 mutant and wild-type groups using R software. The results revealed 2,369 and 165 differentially expressed genes using the edgeR and DESeq packages, respectively. Of these, 161 genes were intersected in both the edgeR and DESeq analyses (Fig. 2A). A volcano plot was constructed using the gene information from the DESeq package (Fig. 2B). The red points indicate the significantly differentially expressed genes, using the criteria of $|\log \mathrm{FC}|>1$ and FDR<0.05. Next, two GEO databases (GSE72094 and GSE75037) of patients with lung adenocarcinoma were used to further validate the differentially expressed genes using the limma package in R software. The results revealed 84 and 218 significantly differentially expressed genes for the GSE72094 and GSE75037 databases, respectively. Finally, by comparing the TCGA and GEO database results, 11 genes were identified to be significantly differentially expressed in all the aforementioned analyses (Fig. 2C). Fig. 1 illustrates the flow-chart for the study design. Table II lists the detailed gene expression information for these 11 genes. A heat map was constructed using the expression information for these 11 genes (Fig. 2D). To better analyze the differential expression data for these genes, scatter plots were created using GraphPad Prism 7 (Fig. 2E).

Gene expression validation. A stably transfected A549 cell line overexpressing wild-type LKB1 was constructed and confirmed via western blot analysis (Fig. 2F). The results demonstrated that the A549 cells transfected with the wild-type LKB1 plasmid had markedly higher wild-type LKB1 protein expression levels compared with cells transfected with empty vector. Next, the expression levels of the 11 significantly differentially expressed genes were examined by RT-qPCR in A549 cells transfected with wild-type LKB1 plasmid and cells transfected with empty vector. FGL1 was selected as the research object for subsequent experiments. RT-qPCR results indicated that FGL1 mRNA expression levels were 
Table II. Differential expression analysis results of 11 genes.

\begin{tabular}{|c|c|c|c|c|}
\hline Gene & Fold change & $\log _{2}$ fold change & P-value & Adjusted P-value \\
\hline ARHGAP20 & 0.265571 & -1.91283 & $5.10 \times 10^{-6}$ & 0.002083 \\
\hline ATP13A4 & 0.315201 & -1.66565 & $4.13 \times 10^{-6}$ & 0.001952 \\
\hline BPIFA2 & 6.039897 & 2.594524 & 0.000373 & 0.035563 \\
\hline CATSPERB & 3.083428 & 1.624535 & 0.000343 & 0.033385 \\
\hline CPS1 & 5.195722 & 2.377324 & 0.00025 & 0.026791 \\
\hline CST6 & 0.297055 & -1.7512 & 0.000207 & 0.024988 \\
\hline CX3CL1 & 0.239601 & -2.0613 & $7.34 \times 10^{-10}$ & $3.82 \times 10-6$ \\
\hline DUSP4 & 3.228106 & 1.690688 & $5.55 \times 10^{-8}$ & $6.80 \times 10-5$ \\
\hline FGL1 & 7.038152 & 2.815197 & $8.38 \times 10^{-6}$ & 0.002908 \\
\hline FXYD4 & 6.417125 & 2.681927 & 0.000434 & 0.039426 \\
\hline HAL & 3.189729 & 1.673434 & 0.000135 & 0.018728 \\
\hline
\end{tabular}

The differential expression information of these 11 genes was obtained by R software using DESeq package. Adjusted P-value is acquired by adjusting P-values using the DESeq package. ARHGAP20, Rho GTPase activating protein 20; ATP13A4, ATPase 13A4; BPIFA2, BPI fold containing family A member 2; CATSPERB, cation channel sperm associated auxiliary subunit $\beta$; CPS1, carbamoyl-phosphate synthase 1; CST6, cystatin E/M; CX3CL1, C-X3-C motif chemokine ligand 1; DUSP4, dual specificity phosphatase 4; FGL1, fibrinogen-like 1; FXYD4, FXYD domain containing ion transport regulator 4; HAL, histidine ammonia-lyase.

significantly decreased in A549 cells transfected with LKB1 plasmid compared with cells transfected with empty vector $(\mathrm{P}<0.0001$; Fig. 2G). FGL1 expression was also verified in using Gene Expression Profiling Interactive Analysis (gepia. cancer-pku.cn/index.html), which is a visualization website for TCGA data that provides differential expression analysis of genes between tumor and normal patients (Fig. 2H). Lung adenocarcinoma patients had high FGL1 expression (Fig. 2H; denoted in red).

Cell proliferation. The present study used four different FGL1-targeting sequences to interfere with FGL1 expression in A549 cells, and their efficiency was evaluated by RT-qPCR (Fig. 3A). The silencing efficiency of the four siRNAs was very high. A549 cells transfected with the FGL1-targeting siRNAs were used in the colony formation assay. Following FGL1 silencing, the cell growth rate was significantly increased (Fig. 3B and C).

EMT. The effect of FGL1 on cell migration was assessed using a wound healing assay. The scratch area of the FGL1-silenced A549 cells was significantly reduced compared with the control A549 cells 48 h post-scratching (Fig. 3D and E), indicating that FGL1 inhibited cell migration. Immunofluorescence staining of the actin filaments with phalloidin was used to observe changes in cell morphology following FGL1 knockdown (Fig. 3F). The cells became long and fusiform-shaped with more angular edges, indicating that the cells had undergone EMT changes. The protein expression levels of FGL1 were further confirmed via western blot analysis in LKB1 mutant lung adenocarcinoma cells (A549 and H157) and LKB1 mutant large cell lung cancer cells (H460); the results demonstrated that transfection with the control siRNA had no effect on FGL1 protein levels, while transfection with the FGL1-targting siRNA (FGL1-3) markedly reduced its protein expression levels (Fig. 3G). The protein expression levels of
EMT-associated markers were then evaluated via western blotting in LKB1 mutant lung adenocarcinoma cells (A549 and H157) and LKB1 mutant large cell lung cancer cells (H460; Fig. 3H). CDH1 expression was lower, while CDH2 and VIM expressions were higher following FGL1 silencing in LKB1 mutant lung adenocarcinoma cells (Fig. 3H). However, CDH1 and VIM expression did not noticeably differ following FGL1 silencing in LKB1 mutant large cell lung cancer cells (Fig. 3H). RT-qPCR was also used to detect the mRNA expression levels of EMT-associated markers in the LKB1 mutant lung adenocarcinoma A549 cells and similar results to those of the western blot analysis were observed (Fig. 3I). These results indicated that FGL1 silencing promoted EMT, and that intrinsic FGL1 expression may inhibit EMT occurrence in LKB1 mutant lung adenocarcinoma.

Angiogenesis. RT-qPCR was used to detect expression changes in angiogenesis-related markers in FGL1-silenced A549 cells. The results revealed higher mRNA expression levels following FGL1 silencing for the angiogenesis-associated markers VEGFA, VEGFB, hypoxia-inducible factor (HIF) $1 \alpha$, insulin-like growth factor-1 (IGF-1) and epidermal growth factor receptor (EGFR), compared with A549 control cells (Fig. 3J). These results suggested that FGL1 silencing promoted angiogenesis in LKB1 mutant lung adenocarcinoma cells.

IHC analysis. Lung cancer tissue samples from 30 patients with lung adenocarcinoma were used for IHC analysis for LKB1 expression (Fig. 4A). Then, the patients that exhibited low LKB1 expression in their lung cancer tissues were selected and grouped by FGL1 expression levels (Fig. 4B). IHC was used to stain for the EMT-associated indicator, $\mathrm{CDH} 2$, and the angiogenesis-related indicator, VEGFA, separately in the low and high FGL1 expression groups (Fig. 4B). CDH2 and VEGFA were highly expressed in the low FGL1 expression group, indicating that low FGL1 expression promoted EMT 


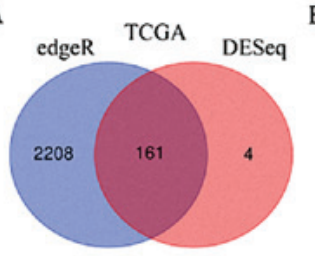

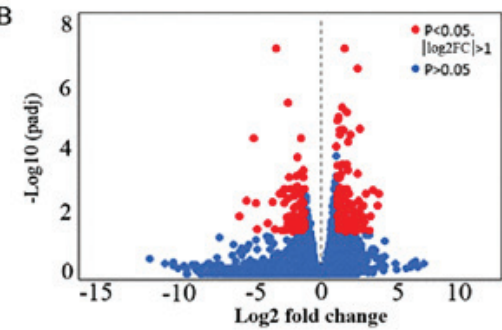

C

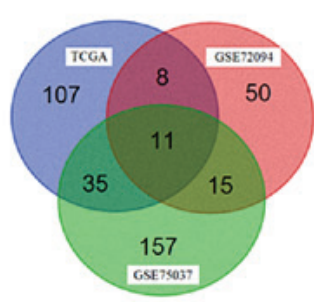

$\mathrm{F}$

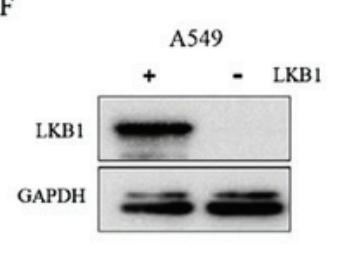

D

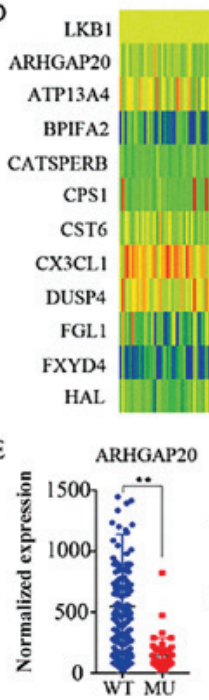

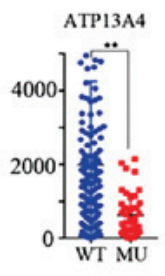

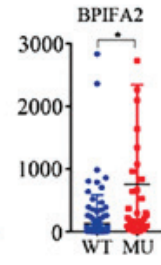

DUSP4

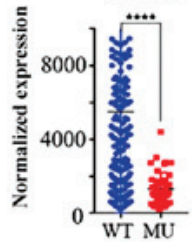

$20000-\left[\begin{array}{ccc}30000 \\ 0\end{array}\right.$

FGL1 FXYD4
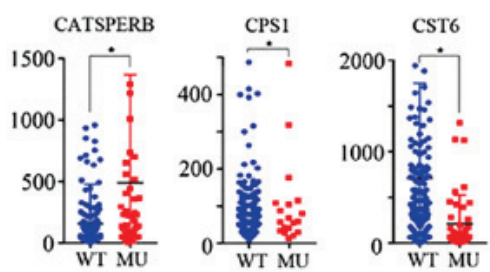

G
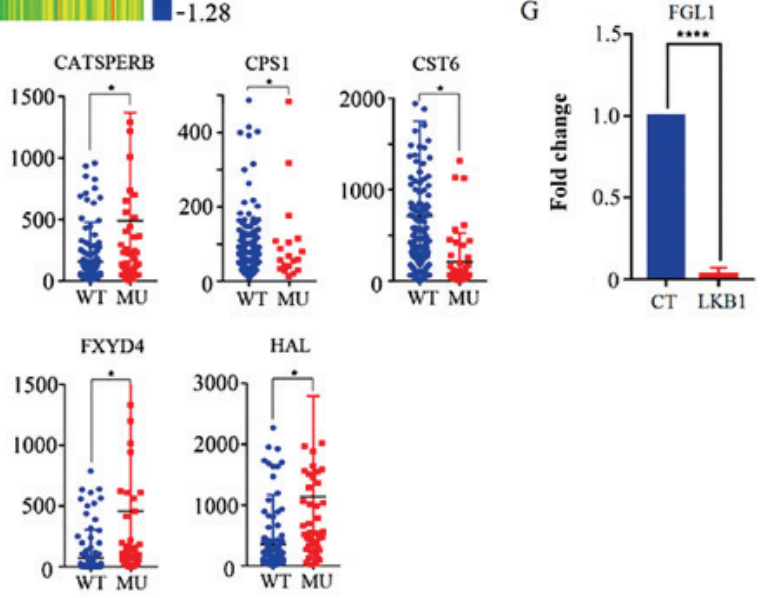

HAL

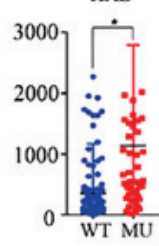

"

Gene expression profile across all tumor samples and paired normal tissues

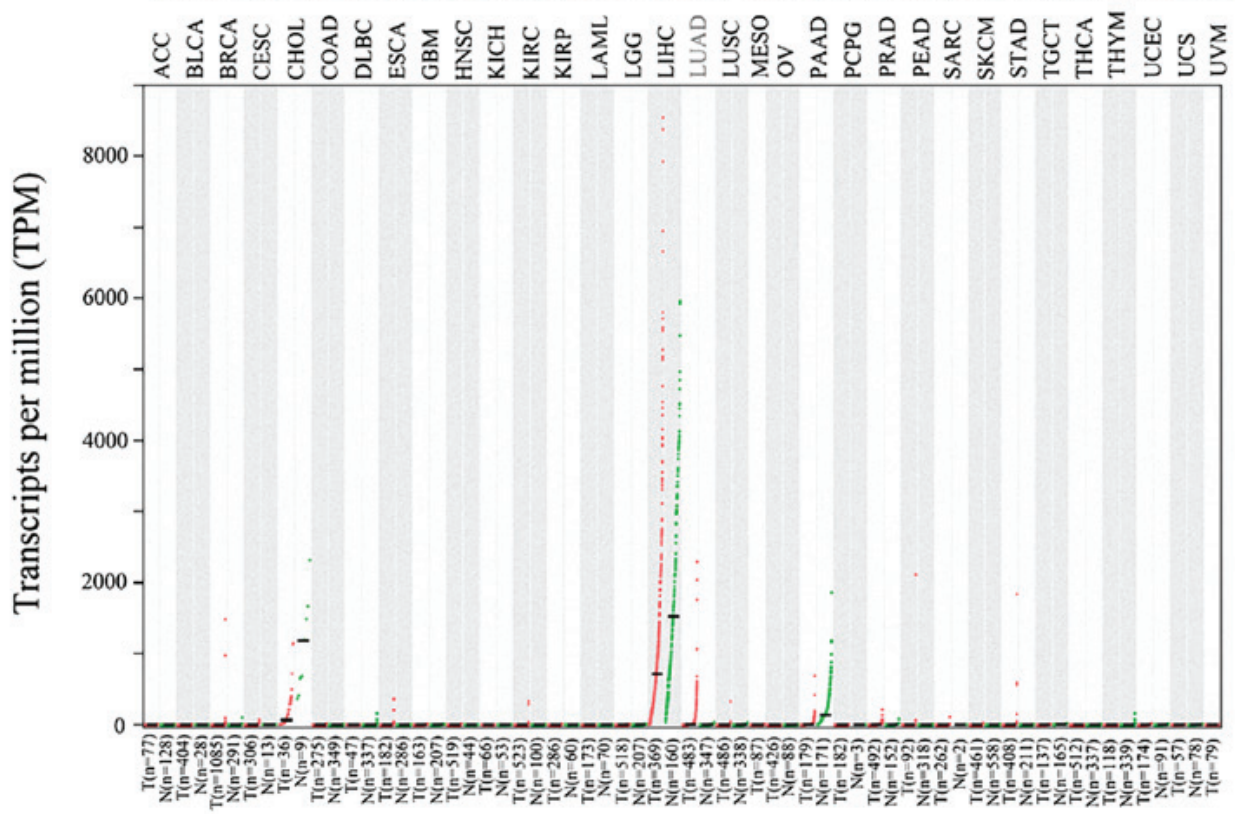

Figure 2. Differential gene expression analysis and validation. (A) Venn diagram of differentially expressed genes in TCGA database analyzed using the edgeR and DESeq packages in R software. (B) Volcano plot of the gene expression analysis acquired with the DESeq package. (C) Eleven significantly differentially expressed genes were identified via intersection of analyses from TCGA and two GEO databases. (D) Heat map of the 11 significantly differentially expressed genes. Blue indicates LKB1 mutant adenocarcinoma patients. (E) Scatter plots of the 11 significantly differentially expressed genes between patients with LKB1 WT and MU lung adenocarcinoma. The specific P-values are listed in Table II. (F) Stable LKB1-overexpressing A549 cells were generated and confirmed via western blotting. (G) FGL1 mRNA expression levels in LKB1-overexpressing and control A549 cells. (H) FGL1 expression verified in lung adenocarcinoma using Gene Expression Profiling Interactive Analysis. ${ }^{*} \mathrm{P}<0.05,{ }^{* *} \mathrm{P}<0.01$ and ${ }^{* * * * *} \mathrm{P}<0.0001$, with comparisons indicated by lines. TCGA, The Cancer Genome Atlas; LKB1, liver kinase b1; FGL1, fibrinogen-like 1; WT, wild-type; MU, mutant; CT, control. 
A

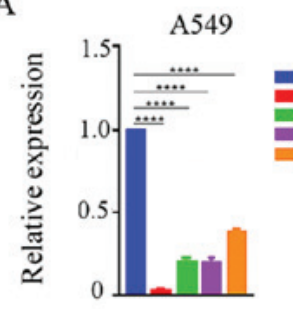

C

Colony formation

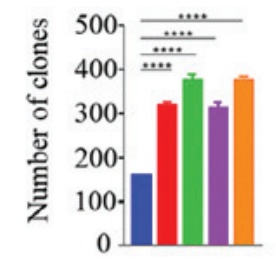

E Wound healing

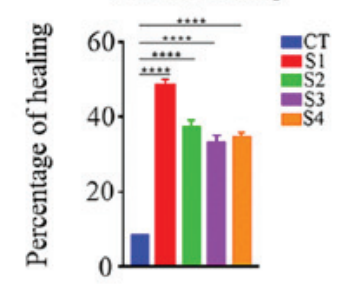

G

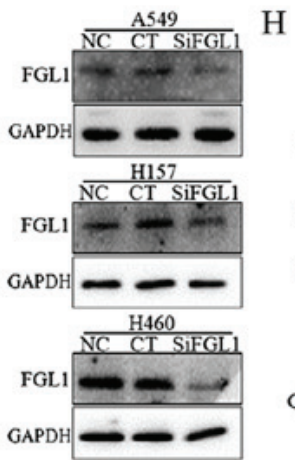

B

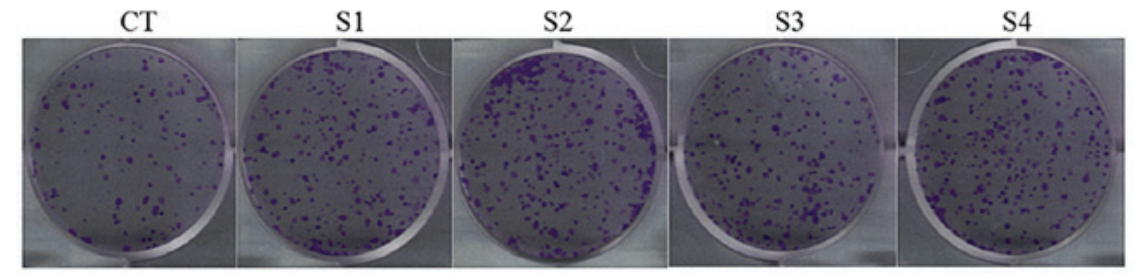

D

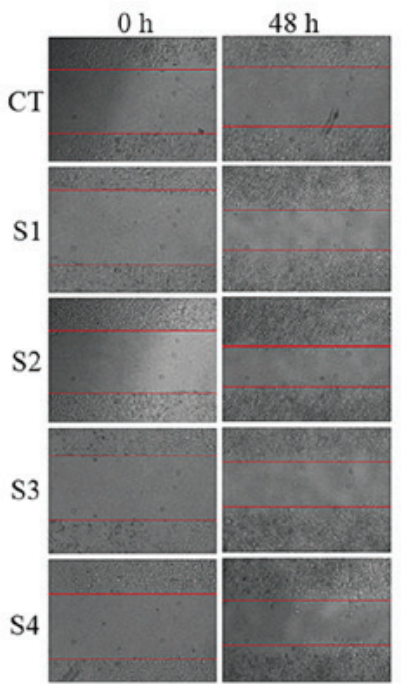

$\mathrm{F}$
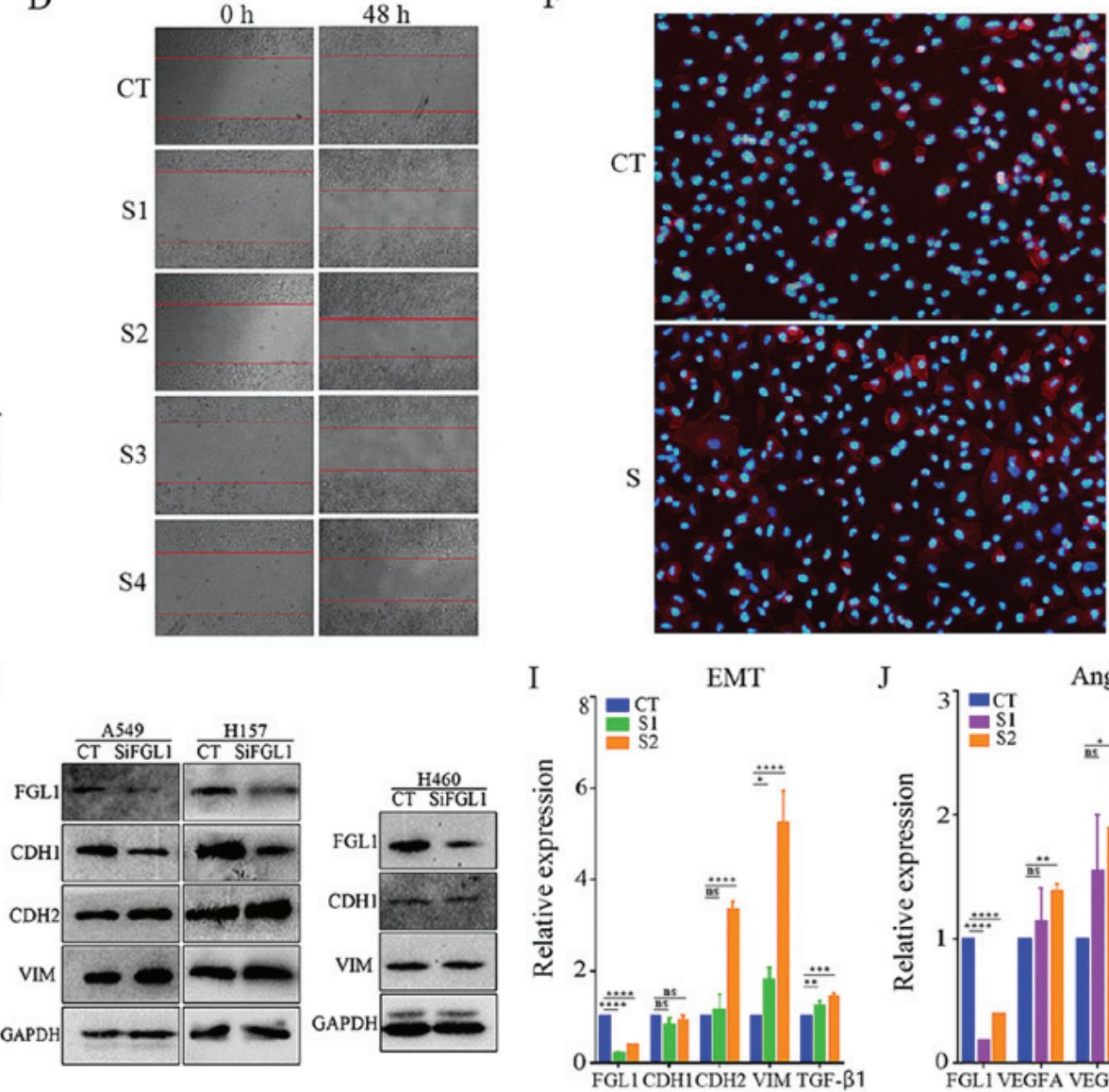

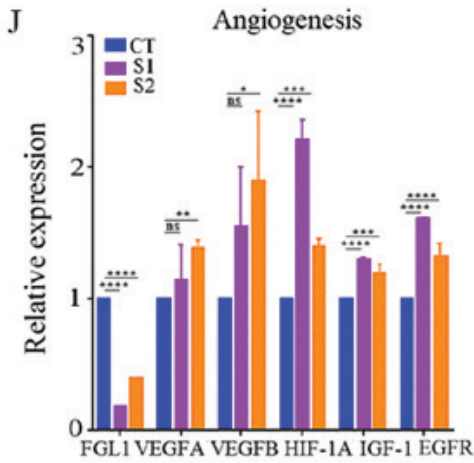

Figure 3. Effect of FGL1 in EMT and angiogenesis-related gene expression in vitro. (A) Verification of FGL1 silencing efficiency by RT-qPCR in A549 cells following siRNA transfection. (B) Colony formation assay of A549 cells following FGL1 silencing. (C) Quantification of the colony formation assay results. (D) Wound healing assay of A549 cells following FGL1 silencing. (E) Quantification of the wound healing assay results. (F) Immunofluorescence staining (x100 magnification) of actin filaments with phalloidin (red) and of nuclei with DAPI (blue). (G) Western blot analysis of FGL1 protein expression levels in LKB1 mutant lung adenocarcinoma cells (A549 and H157) and LKB1-mutant large cell lung cancer cells (H460) following FGL1 silencing. (H) Western blot analysis of EMT-associated markers in LKB1 mutant lung adenocarcinoma cells (A549 and H157) and LKB1-mutant large cell lung cancer cells (H460) following FGL1 silencing. (I) RT-qPCR analysis of EMT-associated markers in A549 cells following FGL1 silencing. (J) RT-qPCR analysis of angiogenesis-associated markers in FGL1-silenced A549 cells. Three independent experiments were performed. ${ }^{*} \mathrm{P}<0.05,{ }^{* * *} \mathrm{P}<0.01,{ }^{* * * *} \mathrm{P}<0.001$ and ${ }^{* * * * *} \mathrm{P}<0.0001$, with comparisons indicated by lines. FGL1, fibrinogen-like 1; EMT, epithelial-mesenchymal transition; RT-qPCR, reverse transcription-quantitative PCR; si, small interfering; LKB1, liver kinase b1; CT, control; S, siRNA-transfected; CDH1, E-cadherin; CDH2, N-cadherin; VIM, vimentin; TGF, transforming growth factor; VEGF, vascular endothelial growth factor; HIF, hypoxia-inducible factor; IGF, insulin-like growth factor; EGFR, epidermal growth factor receptor.

and angiogenesis in LKB1-low lung adenocarcinoma tissue samples.

Gene function enrichment analysis. GSEA was used to further explore the gene function of FGL1 (Fig. 5). Using the TCGA database, lung adenocarcinoma information from 592 patients was acquired. These patients were ranked according to the expression level of FGL1, and the 200 patients with the lowest and highest FGL1 expression were selected. Then these 200 patients were divided into two groups according to FGL1 expression for GSEA analysis. Signaling pathways, such as 'regulation of epithelial cell migration', 'cell adhesion molecules' and 'epithelial cell development', that are associated with EMT, were enriched in the low FGL1 expression group based on the analysis results from both GO and the KEGG (Fig. 5A-F); this further suggested that low FGL1 expression promoted EMT in lung adenocarcinoma patients. The angiogenesis-associated GO signaling pathway 'positive regulation of vasculature development' was also enriched in the low FGL1 expression group (Fig. 5G), indicating that low FGL1 expression promoted angiogenesis in lung adenocarcinoma patients. Finally, two cell growth-associated GO signaling pathways were enriched in the low FGL1 expression group (Fig. 5H and I), indicating that low FGL1 expression promoted cell growth. 
A

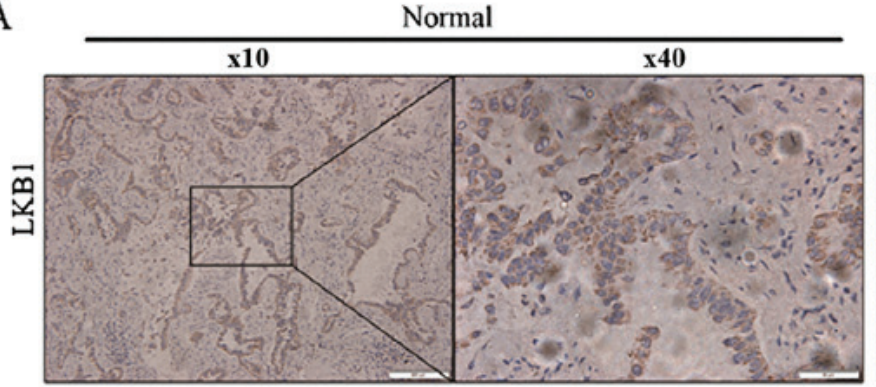

B
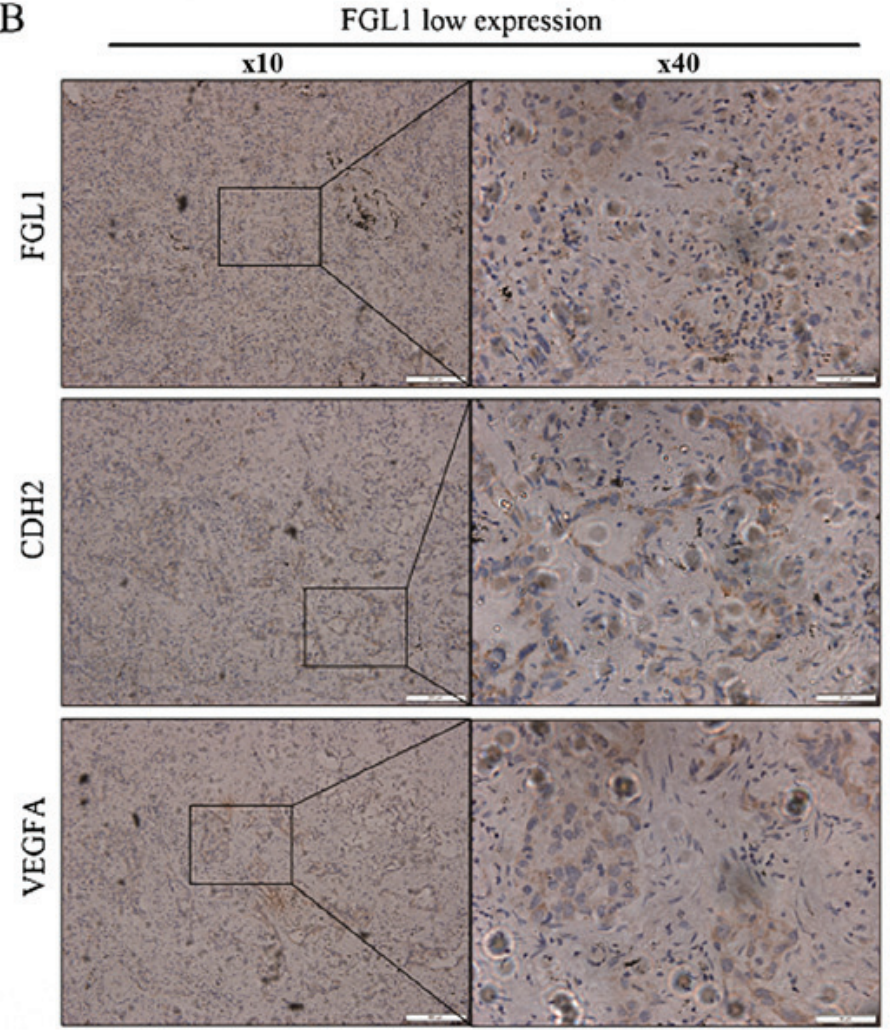

LKBI low expression

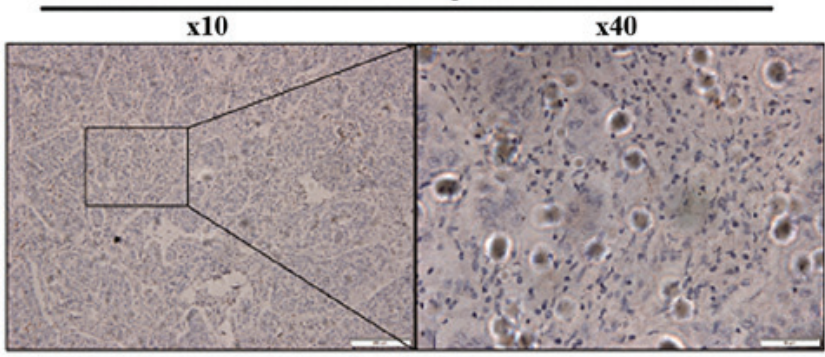

FGLl high expression
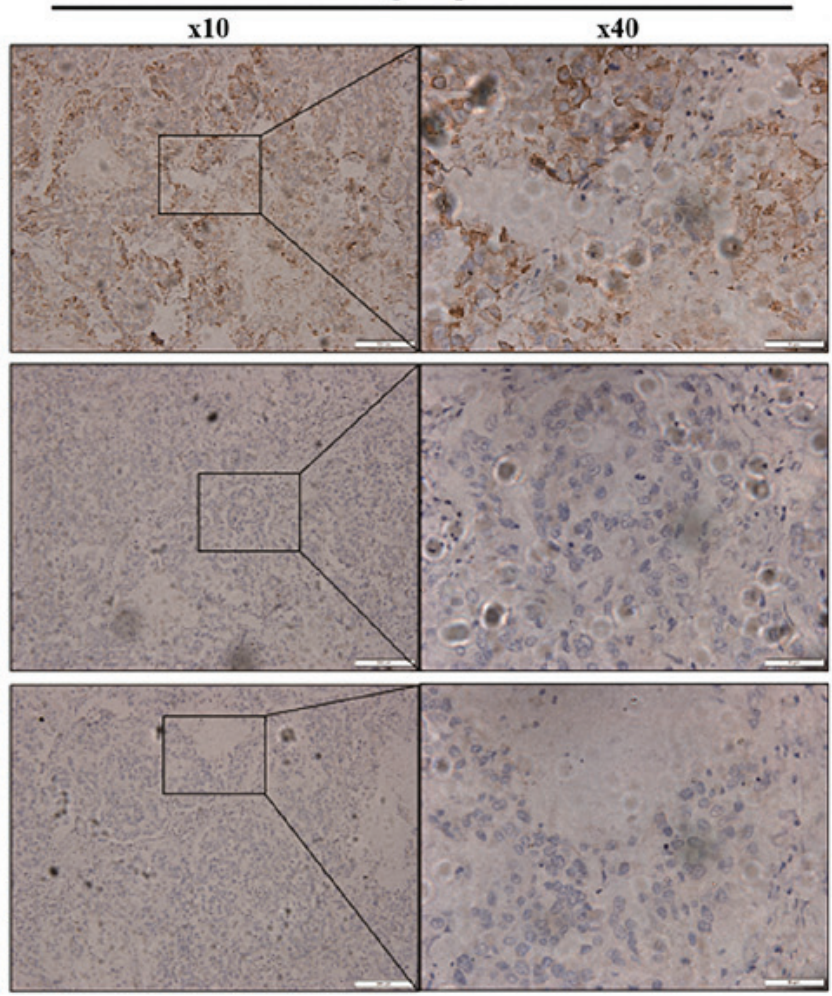

Figure 4. Association of FGL1 expression with EMT and angiogenesis-related markers using IHC. (A) IHC was used to stain for LKB1 in tumor sampled from 30 patients with lung adenocarcinoma. Representative IHC pictures of the high and low LKB1 expression groups are shown at x10 and x40 magnification (scale bars, 200 and $50 \mu \mathrm{m}$, respectively). (B) IHC was used to stain for CDH2 and VEGFA separately in the low and high FGL1 expression groups. Representative IHC pictures are shown at x10 and x40 magnification (scale bars, 200 and $50 \mu \mathrm{m}$, respectively). FGL1, fibrinogen-like 1; EMT, epithelial-mesenchymal transition; IHC, immunohistochemistry; LKB1, liver kinase b1; CDH2, N-cadherin; VEGF, vascular endothelial growth factor.

\section{Discussion}

Although many treatment modalities exist for lung adenocarcinoma, such as surgery (22), radiotherapy (23), chemotherapy (24) and targeted treatment (25), the 5-year survival rate is very low due to late diagnoses and recurrence (26). Many studies are associated with targeted gene treatment, and genes are continually being reported as biomarkers for diagnosis, prognosis and treatment of lung cancer patients (27-29). Zer et al (27) analyzed Kras mutations and concluded that Kras mutant subtypes were not homogeneous in their prognostic and predictive effects. Qiu et al (28) reported that microRNA-499 could be a useful biomarker for predicting poor prognosis for patients with lung cancer. Tang et al (29) conducted a large-scale meta-analysis to evaluate published gene expression prognosis signatures for biomarker-based clinical studies on lung cancer. However, few biomarkers are associated with LKB1 mutant adenocarcinoma. The present study focused on LKB1 mutant adenocarcinoma to discover effective diagnostic, prognostic and therapeutic indicators for these patients. Bioinformatics data mining and experimental verification revealed that FGL1 was significantly highly expressed in LKB1 mutant lung adenocarcinoma; thus, the functional role of FGL1 in LKB1 mutant lung adenocarcinoma was explored.

LKB1 encodes a serine/threonine kinase that directly activates AMPK to regulate lipid, cholesterol and glucose metabolism (30). LKB1 has a high mutation rate in lung adenocarcinoma $(31,32)$, and many studies have examined the role of LKB1 mutation in lung adenocarcinoma. Calles et al (33) reported that loss of LKB1 was a biomarker for more aggressive biology in Kras-mutant lung adenocarcinoma. Gao et al (34) examined the occurrence of LKB1 mutation with EGFR and Kras mutation and demonstrated that Kras and LKB1 had very high co-mutation frequencies. Shackelford et al (35) verified an association between LKB1 mutation and the therapeutic response to the metabolic drug phenformin; phenformin may 
A

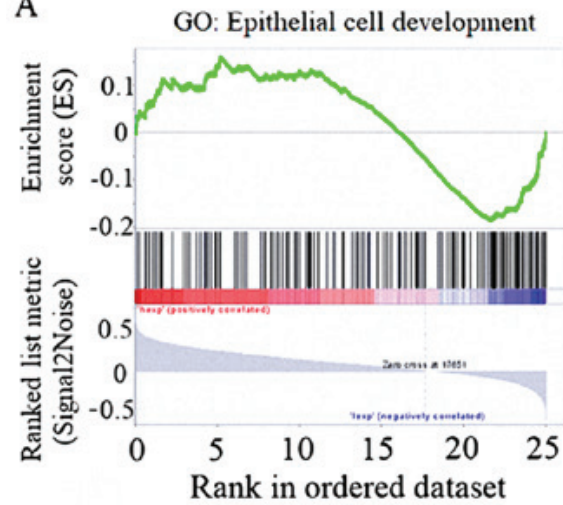

D

KEGG: Cell adhesion molecules CAMs

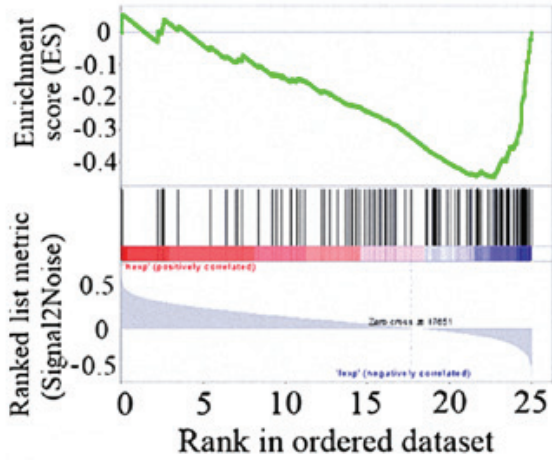

G

GO: Positive regulation of vasculature development

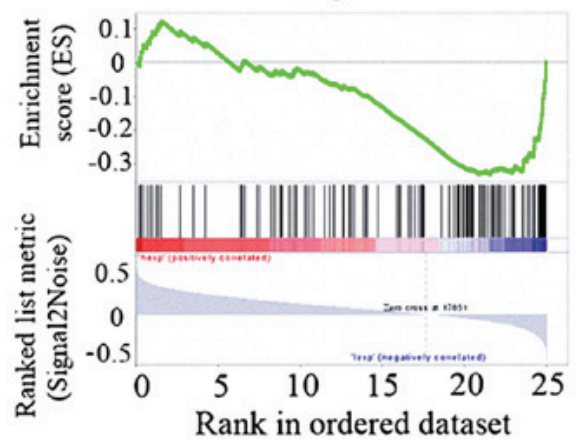

B

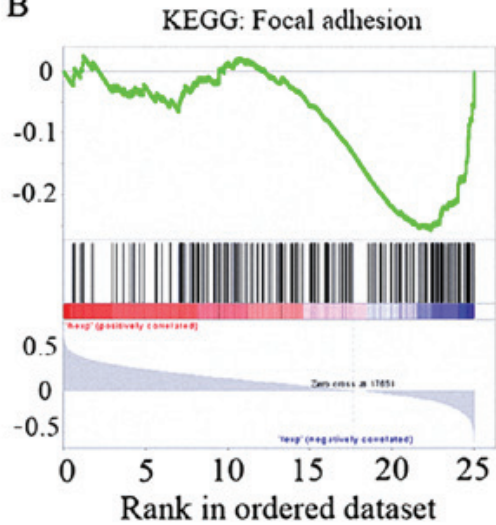

E GO: Single organism cell adhesion

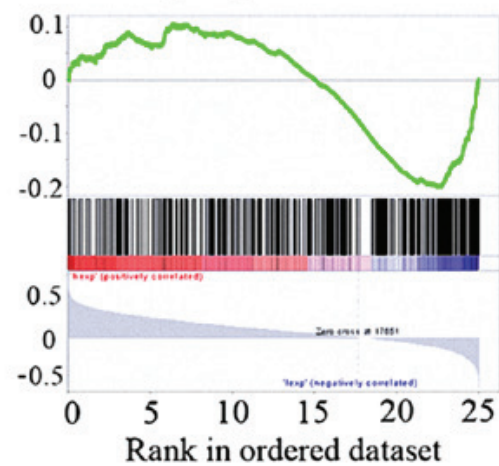

H GO: Regulation of cell activation

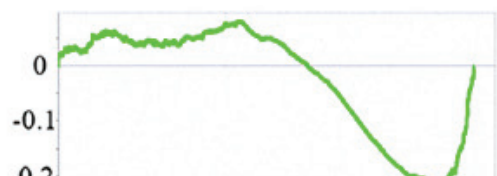

$-0.2$
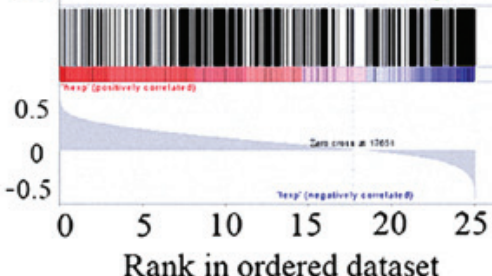

C

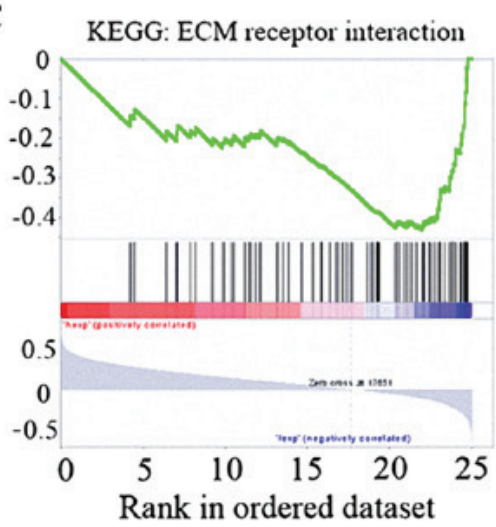

F GO: Regulation of epithelial cell migration

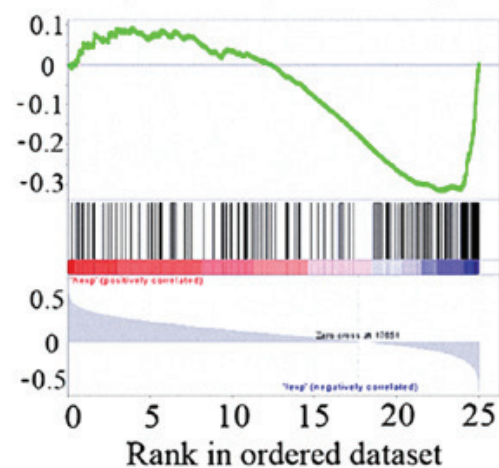

I GO: Regulation of cellular response to growth factor stimulus
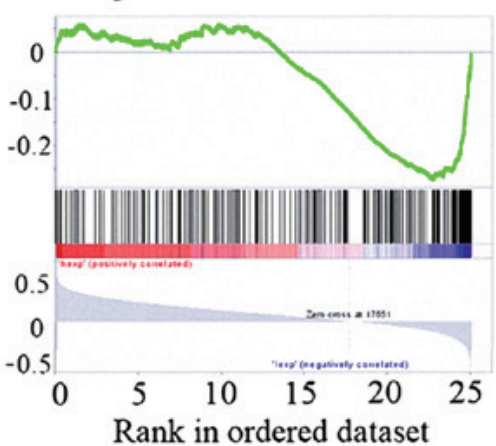

Figure 5. Analysis of FGL1 function using Gene Set Enrichment Analysis. (A-F) EMT-associated signaling pathways were enriched in the low FGL1 expression group. (G) An angiogenesis-associated signaling pathway was enriched in the low FGL1 expression group. (H and I) Cell growth-associated signaling pathways were enriched in the low FGL1 expression group. FGL1, fibrinogen-like 1; EMT, epithelial-mesenchymal transition; GO, gene ontology; KEGG, Kyoto Encyclopedia of Genes and Genomes; ECM, extracellular matrix; CAM, cell adhesion molecule;

act as a cancer metabolism-based therapeutic drug to selectively target LKB1-deficient tumors. These previous studies indicated that LKB1 may have an important role in lung adenocarcinoma; therefore, the present study focused on exploring differential gene expression associated with the LKB1 mutation in lung adenocarcinoma and FGL1 was identified.

Gene expression information of patients with lung adenocarcinoma was downloaded from TCGA and GEO, analyzed and validated by experimentation. FGL1 was significantly highly expressed in LKB1 mutant lung adenocarcinoma; thus, it was evaluated whether FGL1 may be closely associated with LKB1. FGL1 is mainly expressed in the liver and is a secreted protein with mitogenic activity on primary hepatocytes. Demchev et al (36) postulated that FGL1 might have key roles in metabolism and liver regeneration. Zou et al (37) indicated that bone marrow-derived mesenchymal stem cells attenuated acute liver injury by regulating FGL1 expression. Nayeb-Hashemi et al (14) demonstrated that loss of FGL1 accelerated hepatocellular carcinoma development. To the best of our knowledge, the only study focusing on FGL1 in lung cancer was conducted by Wang et al (38), who reported that FGL1 might be a critical EMT effector involved in cellular adhesion and communication. The present results further confirmed that loss of FGL1 was closely associated with EMT in LKB1 mutant adenocarcinoma.

The present study concluded that loss of FGL1 promoted cell growth, the EMT process and angiogenesis in LKB1 mutant lung adenocarcinoma by functional experiments and GSEA analysis. 
Çeliktas et al (39) indicated that LKB1 mutation was closely associated with cell growth, metabolism and prognosis in lung adenocarcinoma. Okon et al (40) concluded that LKB1 inhibited angiogenesis by promoting RAB7-mediated neuropilin-1 degradation. Roy et al (41) verified that LKB1 inactivation triggered EMT in lung cancer cells by inducing zinc finger $\mathrm{E}$ box binding homeobox 1 . These studies were consistent with our findings and provided support for our research.

The present study is the first to link LKB1 and FGL1 and to demonstrate that loss of FGL1 induced EMT and angiogenesis in LKB1 mutant lung adenocarcinoma. Two databases, TCGA and GEO, were used for data mining and FGL1 was identified by gene expression analysis. We combined this information with functional experiments in cell lines in vitro to validate our findings. However, the present study had several limitations. First, our verified experiments were not comprehensive and could not fully explain our conclusion. Second, the present only used two lung adenocarcinoma cell lines (A549 and H157) and one large cell lung cancer cell line (H460) to conduct experiments in vitro and no in vivo experiments were conducted. Furthermore, the exact mechanism by which LKB1 overexpression represses FGL1 expression remains unclear. Overexpression of LKB1 can inhibit anabolism through the AMPK signaling pathway, promotes catabolism, and maintains energy homeostasis in high metabolic cells (such as A549) (42). During this process, since anabolism is inhibited, it may result in a decrease in FGL1 synthesis, resulting in a decrease in the FGL1 expression levels. The exact mechanism needs further experimental verification. Studies on FGL1 are rare, especially in lung cancer. Therefore, the detailed functions of FGL1 require further study.

The present study aimed to explore novel biomarkers in LKB1 mutant lung adenocarcinoma. By data mining of TCGA and GEO databases and in vitro functional experiments, the current results demonstrated that loss of FGL1 induced EMT and angiogenesis in LKB1 mutant lung adenocarcinoma. FGL1 may therefore serve as a new biomarker for indicating EMT and angiogenesis in patients with LKB1 mutant lung adenocarcinoma.

\section{Acknowledgements}

Not applicable.

\section{Funding}

This study was supported by the National Science Foundation of China (grant nos. 81602009 and 81672288) and The Joint Research Funds for Shandong University and Karolinska Institute (grant no. SDU-KI-2019-16).

\section{Availability of data and materials}

The datasets used and analyzed during the current study are available from the corresponding author on reasonable request.

\section{Authors' contributions}

FB, GW and JD designed the experiments. FB, GW, XQ and YW collected and processed the data. $\mathrm{CH}$ and $\mathrm{YW}$ wrote and polished article. All of the authors read and approved the final manuscript.

\section{Ethics approval and consent to participate}

The Ethics Committee of Shandong Provincial Hospital Affiliated to Shandong University approved all experimental protocols involving the use of human tissues. Informed consent was obtained from all participants included in the study.

\section{Patient consent for publication}

Not applicable.

\section{Competing interests}

The authors declare that they have no competing interests.

\section{References}

1. Siegel RL, Miller KD and Jemal A: Cancer Statistics, 2017. CA Cancer J Clin 67: 7-30, 2017.

2. Molina JR, Yang P, Cassivi SD, Schild SE and Adjei AA: Non-small cell lung cancer: Epidemiology, risk factors, treatment, and survivorship. Mayo Clin Proc 83: 584-594, 2008.

3. Torre LA, Bray F, Siegel RL, Ferlay J, Lortet-Tieulent J and Jemal A: Global cancer statistics, 2012. CA Cancer J Clin 65: 87-108, 2015.

4. Soria JC, Ohe Y, Vansteenkiste J, Reungwetwattana T, Chewaskulyong B, Lee KH, Dechaphunkul A, Imamura F, Nogami N, Kurata T, et al: Osimertinib in untreated EGFR-mutated advanced non-small-cell lung cancer. N Engl J Med 378: 113-125, 2018.

5. Dai C, Shen J, Ren Y, Zhong S, Zheng H, He J, Xie D, Fei K, Liang W, Jiang G, et al: Choice of surgical procedure for patients eith mon-dmall-vell lung vancer $\leq 1 \mathrm{~cm}$ or $>1$ to $2 \mathrm{~cm}$ smong lobectomy, segmentectomy, and wedge resection: A Population-based study. J Clin Oncol 34: 3175-3182, 2016.

6. Hemminki A, Markie D, Tomlinson I, Avizienyte E, Roth S, Loukola A, Bignell G, Warren W, Aminoff M, Höglund P, et al: A serine/threonine kinase gene defective in Peutz-Jeghers syndrome. Nature 391: 184-187, 1998.

7. Cancer Genome Atlas Research Network: Comprehensive molecular profiling of lung adenocarcinoma. Nature 511: 543-550, 2014

8. Mihaylova MM and Shaw RJ: The AMPK signalling pathway coordinates cell growth, autophagy and metabolism. Nat Cell Biol 13: 1016-1023, 2011.

9. Wodarz A and Näthke I: Cell polarity in development and cancer. Nat Cell Biol 9: 1016-1024, 2007.

10. Carretero J, Shimamura T, Rikova K, Jackson AL, Wilkerson MD, Borgman CL, Buttarazzi MS, Sanofsky BA, McNamara KL, Brandstetter KA, et al: Integrative genomic and proteomic analyses identify targets for Lkb1-deficient metastatic lung tumors. Cancer Cell 17: 547-559, 2010.

11. Contreras CM, Akbay EA, Gallardo TD, Haynie JM, Sharma S, TagaoO, Bardeesy N, Takahashi M, Settleman J, Wong KK, et al: Lkb1 inactivation is sufficient to drive endometrial cancers that are aggressive yet highly responsive to mTOR inhibitor monotherapy. Dis Model Mech 3: 181-193, 2010.

12. Yamamoto T, Gotoh M, Sasaki H, Terada M, Kitajima M and Hirohashi S: Molecular cloning and initial characterization of a novel fibrinogen-related gene, HFREP-1. Biochem Biophys Res Commun 193: 681-687, 1993.

13. Rijken DC, Dirkx SP, Luider TM and Leebeek FW: Hepatocyte-derived fibrinogen-related protein-1 is associated with the fibrin matrix of a plasma clot. Biochem Biophys Res Commun 350: 191-194, 2006.

14. Nayeb-Hashemi H, Desai A, Demchev V, Bronson RT, Hornick JL, Cohen DE and Ukomadu C: Targeted disruption of fibrinogen like protein-1 accelerates hepatocellular carcinoma development. Biochem Biophys Res Commun 465: 167-173, 2015. 
15. Weinstein JN, Collisson EA, Mills GB, Shaw KR, OzenbergerBA, Ellrott K, Shmulevich I, Sander C and Stuart JM; Cancer Genome Atlas Research Network: The Cancer Genome Atlas Pan-Cancer analysis project. Nat Genet 45: 1113-1120, 2013.

16. Barrett T, Wilhite SE, Ledoux P, Evangelista C, Kim IF, Tomashevsky M, Marshall KA, Phillippy KH, Sherman PM, Holko M, et al: NCBI GEO: Archive for functional genomics data sets - update. Nucleic Acids Res 41: D991-D995, 2013.

17. Schabath MB, WelshEA, Fulp WJ, Chen L, Teer JK, Thompson ZJ, Engel BE, Xie M, Berglund AE, CreelanBC, et al: Differential association of STK11 and TP53 with KRAS mutation-associated gene expression, proliferation and immune surveillance in lung adenocarcinoma. Oncogene 35: 3209-3216, 2016.

18. Girard L, Rodriguez-Canales J, Behrens C, Thompson DM, Botros IW, Tang H, Xie Y, Rekhtman N, Travis WD, Wistuba II, et al: An expression signature as an aid to the histologic classification of non-small cell lung cancer. Clin Cancer Res 22: 4880-4889, 2016.

19. Livak KJ and Schmittgen TD: Analysis of relative gene expression data using real-time quantitative PCR and the 2(-Delta Delta C(T)) method. Methods 25: 402-408, 2001.

20. Subramanian A, Tamayo P, Mootha VK, Mukherjee S, Ebert BL, Gillette MA, Paulovich A, Pomeroy SL, Golub TR, LanderES, et al: Gene setenrichment analysis: A knowledge-based approach for interpreting genome-wide expression profiles. Proc Natl Acad Sci USA 102: 15545-15550, 2005.

21. Mootha VK, Lindgren CM, Eriksson KF, Subramanian A Sihag S, Lehar J, Puigserver P, Carlsson E, Ridderstråle M, Laurila E, et al: PGC-1alpha-responsive genes involved in oxidative phosphorylation are coordinately downregulated in human diabetes. Nat Genet 34: 267-273, 2003.

22. Yan TD, Black D, Bannon PG and McCaughan BC: Systematic review and meta-analysis of randomized and nonrandomized trials on safety and efficacy of video-assisted thoracic surgery lobectomy for early-stage non-small-cell lung cancer. J Clin Oncol 27: 2553-2562, 2009

23. Na F, Wang J, Li C, Deng L, Xue J and Lu Y: Primary tumor standardized uptake value measured on F18-Fluorodeoxyglucose positron emission tomography is of prediction value for survival and local control in non-small-cell lung cancer receiving radiotherapy: meta-analysis. J Thorac Oncol 9: 834-842, 2014.

24. Rossi A, Chiodini P, Sun JM, O'Brien ME, von Plessen C, Barata F, Park K, Popat S, Bergman B, Parente B, et al: Six versus fewer planned cycles of first-line platinum-based chemotherapy for non-small-cell lung cancer: A systematic review and meta-analysis of individual patient data. Lancet Oncol 15: 1254-1262, 2014.

25. Blumenthal GM, Zhang L, Zhang H, Kazandjian D, Khozin S, Tang S, Goldberg K, Sridhara R, Keegan P and Pazdur R: Milestone analyses of immune checkpoint inhibitors, targeted therapy, and conventional therapy in metastatic non-small cell lung cancer trials: A Meta-analysis. JAMA Oncol 3: e171029, 2017.

26. Kulkarni S, Vella E, Coakley N, Cheng S, Gregg R, Ung Y and Ellis PM: The use of systemic treatment in the maintenance of patients with non-small cell lung cancer: A systematic review. J Thorac Oncol 11: 989-1002, 2016.

27. Zer A, Ding K, Lee S, Goss G, Seymour L, Ellis P, Hackshaw A, Bradbury PA, Han L, O'Callaghan CJ, et al: Pooled analysis of the prognostic and predictive value of KRAS mutation status and mutation subtype in patients with non-small cell lung cancer treated with epidermal growth factor receptor tyrosine kinase inhibitors. J Thorac Oncol 11: 312-323, 2016.

28. Qiu F, Yang L, Ling X, Yang R, Yang X, Zhang L, Fang W, Xie C, Huang D, Zhou Y, et al: Sequence variation in mature MicroRNA-499 confers unfavorable prognosis of lung cancer patients treated with platinum-based chemotherapy. Clin Cancer Res 21: 1602-1613, 2015.
29. Tang H,Wang S, Xiao G, Schiller J,Papadimitrakopoulou V, Minna J, Wistuba II and Xie Y: Comprehensive evaluation of published gene expression prognostic signatures for biomarker-based lung cancer clinical studies. Ann Oncol 28: 733-740, 2017.

30. Shackelford DB and Shaw RJ: The LKB1-AMPK pathway: Metabolism and growth control in tumour suppression. Nat Rev Cancer 9: 563-575, 2009.

31. Sanchez-Cespedes M, Parrella P, Esteller M, Nomoto S, Trink B, Engles JM, Westra WH, Herman JG and Sidransky D: Inactivation of LKB1/STK11 is a common event in adenocarcinomas of the lung. Cancer Res 62: 3659-3662, 2002.

32. Fang R, Zheng C, Sun Y, Han X, Gao B, Li C, Liu H, Wong KK, Liu XY, Chen $\mathrm{H}$, et al: Integrative genomic analysis reveals a high frequency of LKB1 genetic alteration in Chinese lung adenocarcinomas. J Thorac Oncol 9: 254-258, 2014

33. Calles A, Sholl LM, Rodig SJ, Pelton AK, Hornick JL, Butaney M, Lydon C, Dahlberg SE, Oxnard GR, Jackman DM, et al: Immunohistochemical loss of LKB1 is a biomarker for more aggressive biology in KRAS-mutant lung adenocarcinoma. Clin Cancer Res 21: 2851-2860, 2015.

34. Gao B, Sun Y, Zhang J, Ren Y, Fang R, Han X, Shen L, Liu XY, Pao W, Chen H, et al: Spectrum of LKB1, EGFR, and KRAS mutations in chinese lung adenocarcinomas. J Thorac Oncol 5: $1130-1135,2010$

35. Shackelford DB, Abt E, Gerken L, Vasquez DS, Seki A, Leblanc M, Wei L, Fishbein MC, Czernin J, Mischel PS, et al: LKB1 inactivation dictates therapeutic response of non-small cell lung cancer to the metabolism drug phenformin. Cancer Cell 23: 143-158, 2013.

36. Demchev V, Malana G, Vangala D, Stoll J, Desai A, Kang HW, Li Y, Nayeb-Hashemi H, Niepel M, Cohen DE, et al: Targeted deletion of fibrinogen like protein 1 reveals a novel role in energy substrate utilization. PLoS One 8: e58084, 2013.

37. Zou Z, Cai Y, Chen Y, Chen S, Liu L, Shen Z, Zhang S, Xu L and Chen Y: Bone marrow-derived mesenchymal stem cells attenuate acute liver injury and regulate the expression of fibrinogen-like-protein 1 and signal transducer and activator of transcription 3. Mol Med Rep 12: 2089-2097, 2015.

38. Wang H, Meyer CA, Fei T, Wang G, Zhang F and Liu XS: A systematic approach identifies FOXA1 as a key factor in the loss of epithelial traits during the epithelial-to-mesenchymal transition in lung cancer. BMC Genomics 14: 680, 2013.

39. Celiktas M, Tanaka I, Tripathi SC, Fahrmann JF, Ảguilar-Bonavides C, Villalobos P, Delgado O, Dhillon D, Dennison JB, Ostrin EJ, et al: Role of CPS1 in cell growth, metabolism and prognosis in LKB1-inactivated lung adenocarcinoma. J Natl Cancer Inst 109: 1-9, 2017.

40. Okon IS, Coughlan KA, Zhang C, Moriasi C, Ding Y, Song P, Zhang W, Li G and Zou MH: Protein kinase LKB1 promotes RAB7-mediated neuropilin-1 degradation to inhibit angiogenesis. J Clin Invest 124: 4590-4602, 2014.

41. Roy BC, Kohno T, Iwakawa R, Moriguchi T, Kiyono T, Morishita K, Sanchez-Cespedes M, Akiyama T and Yokota J: Involvement of LKB1 in epithelial-mesenchymal transition (EMT) of human lung cancer cells. Lung Cancer 70: 136-145, 2010.

42. Shaw RJ, Kosmatka M, Bardeesy N, Hurley RL, Witters LA, DePinho RA and Cantley LC: The tumor suppressor LKB1 kinase directly activates AMP-activated kinase and regulates apoptosis in response to energy stress. Proc Natl Acad Sci USA 101: 3329-3335, 2004. 